\title{
Immunological Response in the Mouse Melanoma Model after Local Hyperthermia
}

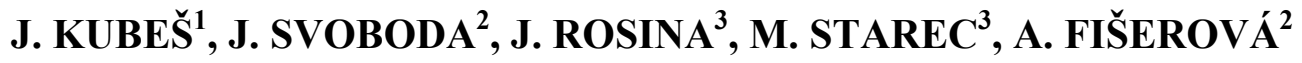 \\ ${ }^{1}$ Department of Radiation Oncology, Faculty Hospital in Ostrava, ${ }^{2}$ Institute of Microbiology of the \\ Academy of Sciences, Prague, ${ }^{3}$ Third Faculty of Medicine, Charles University, Prague, Czech \\ Republic.
}

Received February 15, 2007

Accepted April 18, 2007

On-line May 30, 2007

\begin{abstract}
Summary
Our study was aimed to characterize the phenotype and functional endpoints of local microwave hyperthermia (LHT, $42{ }^{\circ} \mathrm{C}$ ) on tumor infiltrating and spleen leukocytes. The effectiveness of LHT applied into the tumor of B16F10 melanoma-bearing C57/BL6 mice was compared with anesthetized and non-treated animals. Subpopulations of leukocytes were analyzed using the flow cytometry, and the cytotoxic activity of splenocytes against syngeneic B16F10 melanoma and NK-sensitive YAC-1 tumor cell lines was evaluated in ${ }^{51} \mathrm{Cr}$-release assay. Similarly, the in vitro modification of the heat treatment was performed using healthy and melanomabearing splenocytes. We found a $40 \%$ increase of activated monocytes $(\mathrm{CD} 11 \mathrm{~b}+\mathrm{CD} 69+)$ infiltration into the tumor microenvironment. In the spleen of experimental animals, the numbers of cytotoxic T lymphocytes (CTLs-CD3+CD8+) and NK cell $(\mathrm{CD} 49 \mathrm{~b}+\mathrm{NK} 1.1+)$ raised by $22 \%$ and $14 \%$, respectively, while the NK1.1+ monocytes decreases by $37 \%$. This was accompanied by an enhancement of cytotoxic effector function against B16F10 and YAC-1 targets in both in vivo and in vitro conditions. These results demonstrate that LHT induces better killing of syngeneic melanoma targets. Furthermore, LHT evokes the homing of activated monocytes into the tumor microenvironment and increases the counts of NK cells and CTL in the spleen.
\end{abstract}

\section{Key words}

Local hyperthermia • Melanoma • Cytotoxic cells • Monocytes • CD69

\section{Corresponding author}

Jiri Kubes, Department of Radiation Oncology, Faculty Hospital in Ostrava, 17. listopadu 1790, 708 52, Ostrava, Czech Republic. E-mail: jiri.kubes@fnb.cz

\section{Introduction}

The use of hyperthermia (HT - heating of tissue to $41-44{ }^{\circ} \mathrm{C}$ ) is one of the promising methods in cancer treatment (Van der Zee 2002, Baronzio et al. 2006). Although the molecular mechanisms of this process are not fully understood yet, possible effects are: 1) direct cytotoxicity (Milani and Noessner 2006), 2) inhibition of DNA-repair procedures (Kampinga et al. 2004), 3) changes in capillary blood flow and microvessels (Emami et al. 1980) and 4) immunomodulatory effects (Hildebrandt et al. 2002). Relative contributions of the above stated effects are still not fully clarified and are presumably dependent on tumor type (Ostapenko et al. 2005).

Hyperthermia is being introduced either as localized (LHT) or as a whole body hyperthermia (WBH) in various temperature ranges. During $\mathrm{WBH}$, the elevation of temperature near tumoricidal levels $\left(\mathrm{T} \geq 42{ }^{\circ} \mathrm{C}\right) \quad$ leads to the inhibition of host immunocompetence (Huang et al. 1996, Shen et al. 1994), making such arrangement unsuitable for immunological studies. On the other hand, the feverrange temperatures $\left(39-41{ }^{\circ} \mathrm{C}\right)$ show an immunoregulatory advantage by enhanced secretion of immunoglobulins (Ostapenko et al. 2005).

In case of LHT, even if the heating of tumor exceeds $42{ }^{\circ} \mathrm{C}$, the surrounding healthy tissue usually remains at fever-range temperatures $\left(39-41{ }^{\circ} \mathrm{C}\right)$. This selectivity is beneficial, because LHT combines the tumoricidal effect of the heating with the fever-induced immunostimulation. 
Immunomodulatory effect of HT can consist of augmenting of antigenicity of tumor cells, followed by induction of the immune response. More efficient antigen presentation on tumor cells and stimulation of immunocompetent cells was demonstrated in vitro (Ito et al. 2001) and in vivo using LHT (Basu and Srivastava 2003) or WBH (Atanackovic et al. 2002). The current knowledge of the LHT influence on immunological changes encompasses the activation of spleen cells (Vartak et al. 1996), natural killer (NK) cells (Szmigielski et al. 1991), CD8+ (Tc or CTL) cells (Ostapenko et al. 2005) and CD4+ (Th) cells (Stawarz et al. 1993) at temperatures within the fever-range (39-41 $\left.{ }^{\circ} \mathrm{C}\right)$.

In our study, we investigated the effect of LHT on in vivo and in vitro induction of NK and CTLmediated cytotoxic activity against B16F10 melanoma targets. We evaluated changes in effector cell numbers, activation, and killing activity in the spleen and the tumor site after in vivo LHT application. To distinguish effects on effector and target cells, we examined the LHT impact in vitro, with consequent functional studies. We demonstrated that the response to LHT is not a singlestep event, but a cascade of actions ranging from tumor infiltration, possible augmentation of antigen presentation and effector cells proliferation to the activation of terminal cytotoxic cell function.

\section{Methods}

\section{Experimental animals}

Eight-week-old inbred male C57/BL6 mice were purchased from Charles River (D). The mice were housed under natural day/night conditions $\left(22{ }^{\circ} \mathrm{C}, \quad 55 \%\right.$ humidity) and fed a commercial pelleted diet (ST1, Velaz, Prague) ad libitum. The ex vivo experiments started at least 2 weeks after the arrival of the animals to avoid immunological changes caused by transportation stress. The mouse melanoma cell line - B16F10 derived from C57/BL6 mice (kindly donated by Weizmann Institute, Rehovot, Israel) was used in the syngeneic tumor model. B16F10 cells $\left(10^{6} /\right.$ mouse in $\left.0.1 \mathrm{ml} \mathrm{PBS}\right)$ were inoculated subcutaneously (s.c.) into the lower back at day 0 . Mice with tumors reaching $1-2 \mathrm{~cm}$ in greatest dimension were randomly divided into three groups: 1) anesthetized mice treated with hyperthermia (HT), 2) anesthetized mice (anest), and 3) non-treated controls (control). All procedures were conducted in accordance with the European Convention for the Care and Use of
Laboratory Animals as approved by the Czech Animal Care and Use Committee.

\section{Hyperthermia}

Local hyperthermia was performed under anesthesia (ketamine: $1.9 \mathrm{mg} / \mathrm{mouse}$ and xylazine: $0.25 \mathrm{mg} / \mathrm{mouse}$ weighing 25-30 g, i.p.). A microwave generator with working frequency $2450 \mathrm{MHz}$ and power $10 \mathrm{~W}$ was used for tumor heating, in connection with the applicator constructed at the Czech Technical University (Prague, CZ) based on conventional waveguide, with the effective aperture $2 \times 2 \mathrm{~cm}$. The superficial, intra-tumor and rectal temperature of mice was monitored during the whole period of HT application by the fluoro-optic thermometer (LUXTRON, Luxtron Corporation CA). Target temperature $\left(42{ }^{\circ} \mathrm{C}\right)$ in the tumor was reached during one minute and was maintained using pulses of microwaves for $7 \mathrm{~min}$. Rectal temperature did not surpass $38{ }^{\circ} \mathrm{C}$. We performed three consecutive heatings in the hyperthermia group at days 10, 14 and 17 after tumor cells inoculation. Animals in the anesthesia group were anesthetized in the same time intervals as mice in the HT group, but without hyperthermia. Twelve hours after the third session of hyperthermia all mice were euthanized and tumors and spleens were removed for further separation.

\section{Isolation of mouse spleen cells (SC) and tumor infiltrating leukocytes (TIL)}

Spleens were dissociated through a nylon mesh, repeatedly washed and used immediately for flow cytometry (FACS) or in vitro experiments. Tumor infiltrating leukocytes (TILs) were prepared from individual melanomas minced with scissors, eluted by repeated pipetting, and mononuclear cells separated on Ficoll-Hypaque density gradient (1.086). Freshly separated mononuclear cells were used for further phenotype and functional assays.

\section{Cell cultures and in vitro experiments}

Established cell lines YAC-1 (mouse NKsensitive $\mathrm{T}$ lymphoma) and B16F10 (mouse melanoma) were maintained in RPMI-1640 medium supplemented with $2 \mathrm{mM}$ L-glutamine, $1 \mathrm{mM}$ sodium pyruvate, $0.05 \mathrm{mM}$ 2-mercaptoethanol, antibiotics $(0.05 \mathrm{mg} / \mathrm{ml}$ gentamycin, $25 \mathrm{mg} / \mathrm{ml}$ amphotericin B) and $10 \%$ heatinactivated fetal calf serum - FCS (Gibco, Grand Island, NY, USA).

The cytotoxic activity assays of mouse spleen 

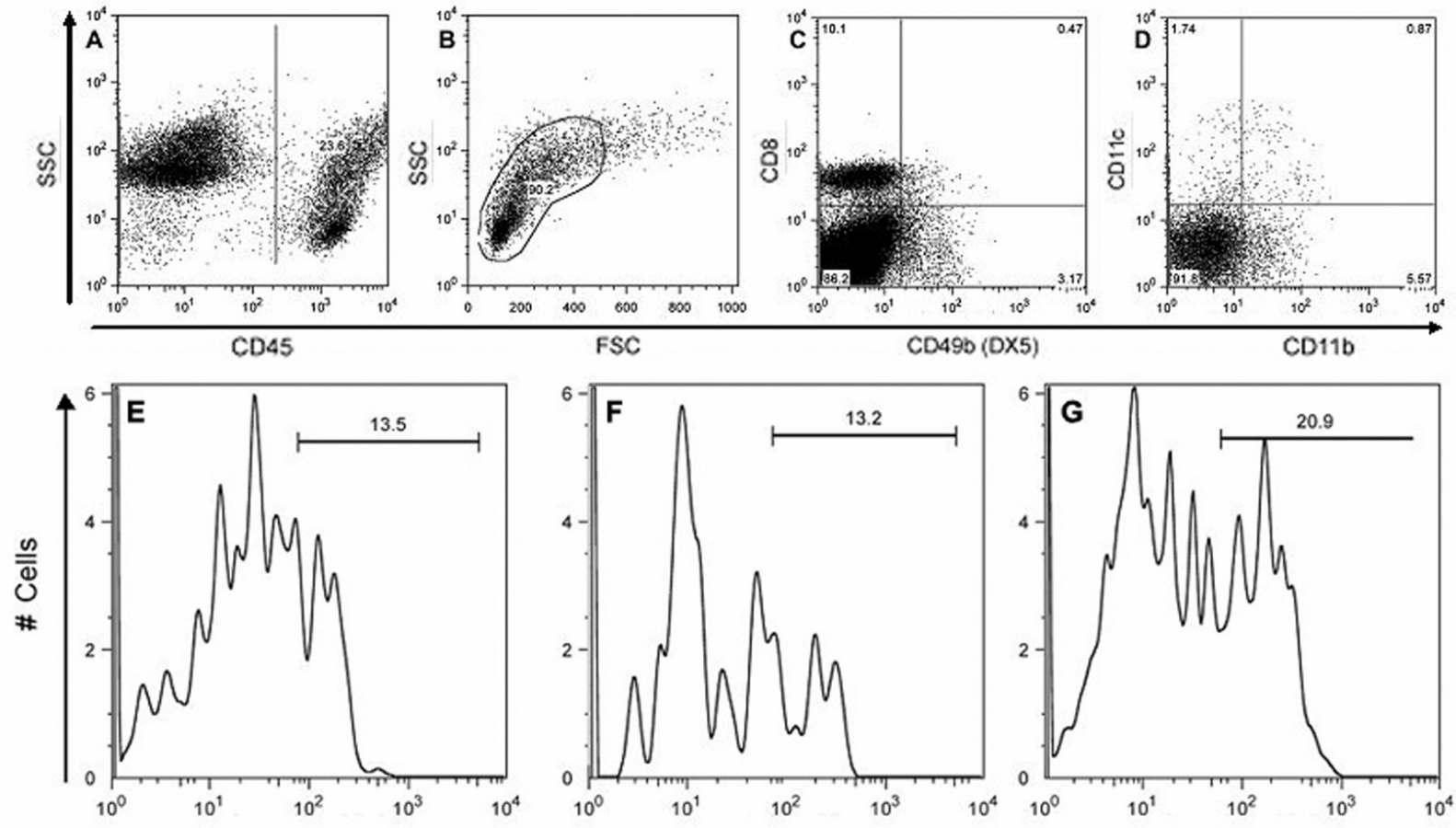

CD69

Fig. 1. Cell surface markers FACS analysis. PI negative (not shown) and CD45 positive cells (A), with lymphocyte/monocyte morphology (B), were analyzed for expression of surface markers of NK/CTL cells (C) and monocyte/DC subpopulation (D). These subsets were further analyzed for CD69 expression (E, F, G), which changed significantly only in case of CD45+/CD49b-CD8-/CD11b+CD11c- cells (monocytes) comparing the hyperthermed animals $(G)$ to controls $(E)$ and anesthetized groups $(F)$. Histograms $(E, F, G)$ represent the percentage of CD69 positive cells out of the gated parental population (CD45+, CD49b-/CD8-/CD11b+/CD11c-). Figure shows an illustrative example of four consecutive experiments with similar results.

cells were performed in RPMI 1640 medium supplemented with L-glutamine, gentamycin and $5 \%$ FCS. Incubation was carried out at $37^{\circ} \mathrm{C}$ in a humidified atmosphere containing $5 \% \mathrm{CO}_{2}$ in a $\mathrm{CO}_{2}$ incubator (Jouan, France).

For in vitro modification of hyperthermia, B16F10 cell line (as target) and splenocytes (as effectors) were cultivated at $37{ }^{\circ} \mathrm{C}$ or $42{ }^{\circ} \mathrm{C}$, in a humidified atmosphere, and $5 \% \mathrm{CO}_{2}$. The effector or target cells were transferred into prewarmed cultivation medium for the heat treatment and the incubation at $42{ }^{\circ} \mathrm{C}$ for $10 \mathrm{~min}$ followed, once or three times in the same schedule as in the in vivo model. The melanoma cells were then harvested and used as targets in cytotoxic assays.

\section{Flow cytometry}

Individual cell suspensions prepared from the spleen and tumor were resuspended in PBS with $0.1 \%$ gelatin (gelatin from cold water fish skin - Sigma) and $0.01 \%$ sodium azide. Phenotypes of cells were determined using specific surface markers for T lymphocytes - CD3PECy5 (17A2), CD4-FITC (H129.19), CD8-PE (53-6.7), B-lymphocytes -CD45R/B220-Alexa405 (RA3-6B2), monocytes, APCs - CD11b-Pacific Blue (M1/70.15), CD11c-FITC (HL3), NK cells - CD49b-FITC (DX5), activation antigens NK1.1-PECy7 (PK136), CD69-PECy5 (H1.2F3) and analysis was performed by FACS LSR II (Becton-Dickinson, USA). Five- or six-color staining was performed according to the manufacturer's standard protocol. The CD45-PECy7 (30-F11) leukocyte common antigen (LCA) staining was applied to distinguish the leukocytes from residual melanoma cells in TIL fraction. Further, the PI negative (live) CD45 positive (leukocytes, Fig. 1A) cells with lymphocyte and monocyte morphology were gated (large lymphomonogate, SSC vs FSC, Fig. 1B) and analyzed for surface markers expression (Fig. 1C,D). Monoclonal antibodies were purchased either from Pharmingen (San Diego, CA, USA) or Caltag (San Francisco, CA). Evaluation of data was performed using FlowJo version 6.1.1 software (Tree Star Inc., Ashland, OR, USA).

\section{Cytotoxicity assay}

Cell-mediated cytotoxicity was estimated using standard ${ }^{51} \mathrm{Cr}$-release assay with splenocytes of experimental animals as effectors. YAC-1, mouse NK- 


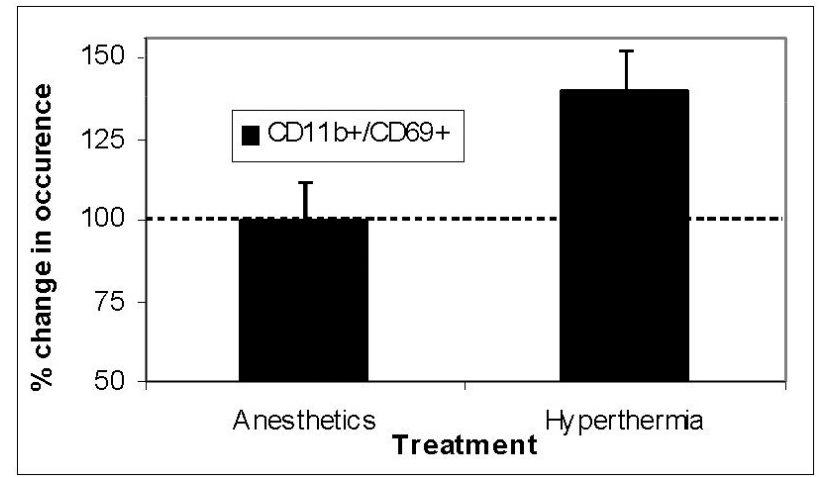

Fig. 2. Proportion of activated monocytes (CD11b+/CD69+) occurrence in TIL fraction. Both control and anesthetized groups showed $12 \pm 1.7 \%$ of $\mathrm{CD} 11 \mathrm{~b}+/ \mathrm{CD} 69+$, while $\mathrm{HT}$ treated group had $17 \pm 2.6 \%$ of $\mathrm{CD} 11 \mathrm{~b}+/ \mathrm{CD} 69+$, showing a $40 \%$ increase. The percentage was counted from CD45 positive cells in the TIL fraction and is shown as percentage change relative to control stated as $100 \%$ (dashed line).

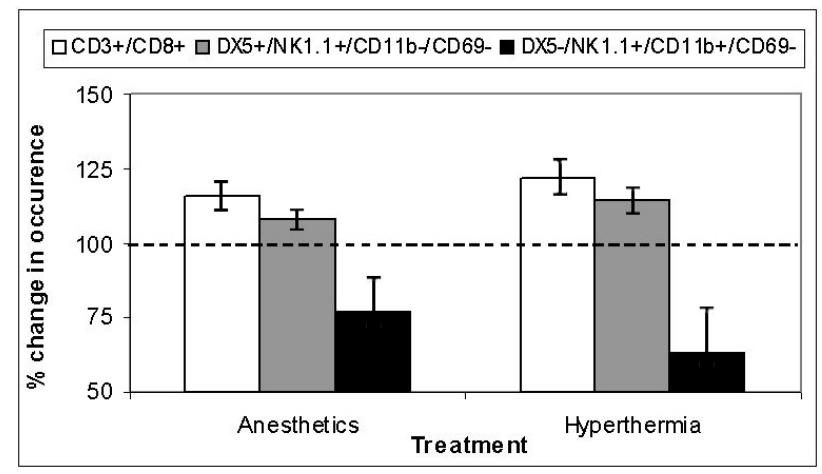

Fig. 3. Distribution of immune cell subpopulations in the spleen after local hyperthermia. The values are presented as percentage changes in occurrence relative to individual controls. The control values (stated as $100 \%$, dashed line) were for CTLs - $55 \%$ (CD8+ out of CD3+); for NK cells - 36\% (NK1.1+ out of $\mathrm{CD} 49 \mathrm{~b}+$ ); for NK1.1 positive monocytes $-17.5 \%$ (NK1.1+ out of $\mathrm{CD} 11 \mathrm{~b}+)$. The data represent mean \pm S.D. of three performed experiments (5-7 animals per group).

sensitive, and B16F10 melanoma cell lines were used as target cells and were labeled by 60-min incubation with $\mathrm{Na}_{2}{ }^{51} \mathrm{CrO}_{4}$ in round-bottomed 96-well microtiter plates (NUNC), at $37^{\circ} \mathrm{C}$ in a humidified atmosphere containing $5 \% \mathrm{CO}_{2}$. Evaluation of effector cell lytic activity against $10^{4}$ target cells was performed after $4 \mathrm{~h}$ of incubation as described previously (Fišerová et al. 1997). The cell free supernatants were harvested $(0.025 \mathrm{ml} / \mathrm{sample}), 0.1 \mathrm{ml}$ of scintillation cocktail (SuperMix, Wallac, Finland) was added, and radioactivity was measured using scintillation counter Microbeta Trilux (Wallac, Finland).

\section{Statistical analysis}

Results in groups were analyzed using one-way analysis of variance (ANOVA), $\mathrm{P} \leq 0.05$ values were considered significant.

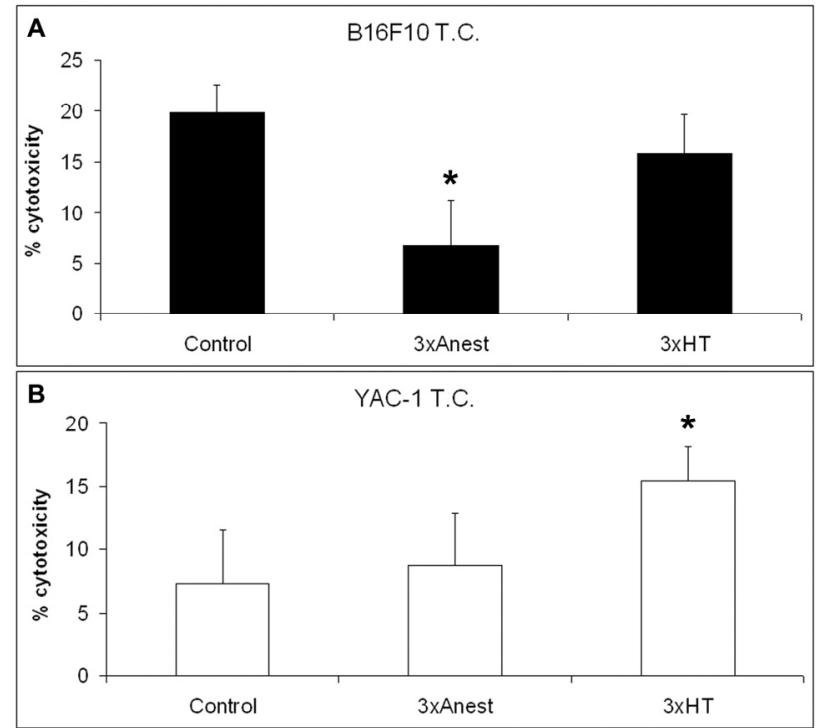

Fig. 4. The specific (A) and natural (B) cytotoxic activity of splenocytes against syngeneic B16F10 melanoma or NK-sensitive YAC-1 target cells in E:T ratio of 32:1 after in vivo applied local hyperthermia. Specific cytotoxicity against B16F10 melanomas was impaired by the use of anesthetics - this effect was countered by a concurrent use of hyperthermia (A). No attenuating effect of anesthetics was observed in NK-mediated cytotoxicity (B). Significant changes relative to non-treated mice are marked by asterisk (* $p \leq 0.05 ; * * p \leq 0.01)$.

\section{Results}

Our results did not include the clinical parameters (tumor growth, survival), since the experiments were designed as short-term schedules after three courses of LHT treatment dedicated to the changes of immune parameters. We performed four consecutive experiments with 22 mice in the heat-treated group (HT), 17 mice in the anesthetized group (anest) and 16 animals in the untreated group (control) to evaluate LHT effects on the immune response of tumor-bearing animals and the distribution of leukocytes in different compartments (spleen, tumor). The subpopulation specific and activation markers were estimated using polychromatic FACS analysis for determination of the LHT effects on the immune cells proportion, and activation. Functional activities of cytotoxic cells (NK, CTL) were measured by standard ${ }^{51} \mathrm{Cr}$-release assay in both in vivo and in vitro arrangements.

\section{LHT-evoked changes in tumor microenvironment}

We have determined the distribution of tumor infiltrating leukocytes (TIL) in tumors using FACS. We did not find any significant changes between the control, anesthetized and the LHT groups in proportion of CTLs, $\mathrm{NK}$ or APC cells in tumor microenvironment. 


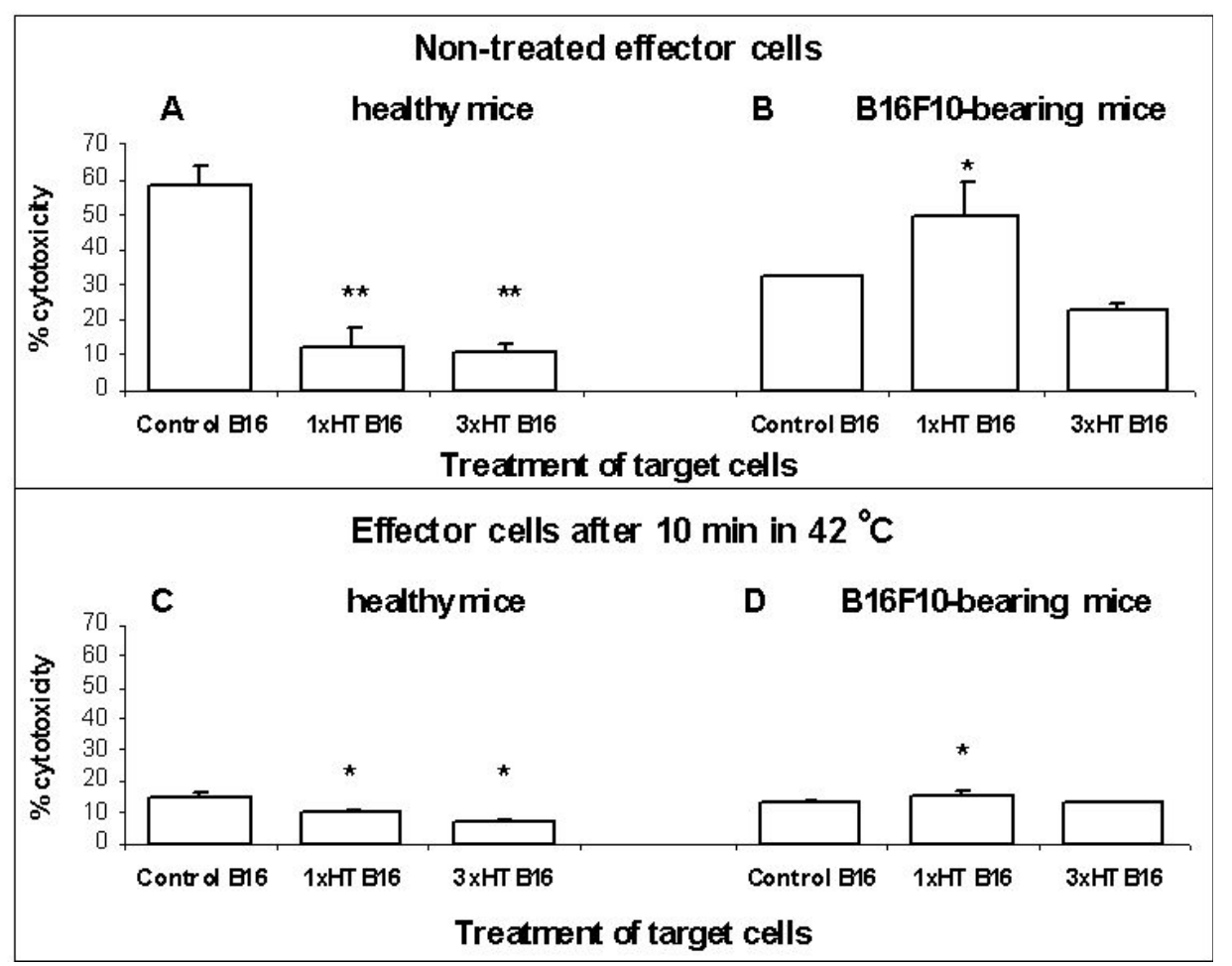

Fig. 5. Splenocyte cytotoxicity against B16F10 melanoma targets after in vitro applied $\mathrm{HT}$ to effectors and/or target cells. Cytotoxicity of splenocytes isolated from healthy $(A, C)$ or B16F10 melanoma-bearing (B, D) mice against pretreated syngeneic $\mathrm{B} 16 \mathrm{~F} 10$ cell line: Control - untreated, $1 \times$ HT B16 or 3 x HT B16 - hyperthermed $\mathrm{B} 16 \mathrm{~F} 10$ cells one or three times, respectively $\left(10 \mathrm{~min}\right.$ at $42^{\circ} \mathrm{C}$ ). Effector cells were incubated for $10 \mathrm{~min}$ in either $37^{\circ} \mathrm{C}(\mathrm{A}, \mathrm{B})$ or $42{ }^{\circ} \mathrm{C}(C, D)$. Cytotoxic assay was performed in E:T ratio $32: 1$, data represent mean \pm S.D. of three experiments done in quintuplicates for each sample. Significant changes relative to non-treated mice are marked by asterisk $(* p \leq 0.05 ; * * p \leq 0.01)$.

Further we have investigated the changes of very early activation antigen CD69 on different TIL subpopulations - NK, CTL, APC, DC (Fig. 1E, 1F, 1G). Our results (Fig. 2) demonstrated enhanced expression of CD69 only in the monocyte population (CD8-/CD49b$/ \mathrm{CD} 11 \mathrm{~b}+/ \mathrm{CD} 11 \mathrm{c}-)$. The counts of activated monocyte $(\mathrm{CD} 11 \mathrm{~b}+/ \mathrm{CD} 69+)$ in both control and anesthetized mice were similar, $12 \pm 1.7 \%$, while the LHT-treated group showed a $40 \%$ increase $(17 \pm 2.6 \%)$ in the TIL fraction.

\section{LHT effect on distribution of immune cells in the spleen}

Our study revealed changes in the occurrence of cell subpopulations in secondary lymphoid organ, the spleen, after the LHT application. The parameters of detected surface markers were similar as for the analysis of TILs (Fig. 1) without CD45 staining. Cytotoxic T lymphocytes $(\mathrm{CD} 3+/ \mathrm{CD} 8+)$ increased their counts by $22 \%$, natural killer cells (CD49b+/NK1.1+) increased by

\section{Direct effect of heat treatment on melanoma and/or} effector cells in vitro

To omit the effect of anesthesia, and to distinguish the role of hyperthermia on either tumor or lymphoid cell populations, we performed an in vitro modification of the experiments. In this procedure, we used splenocytes from healthy or B16F10 melanomabearing mice as effectors and B16F10 melanomas from in vitro cultures as targets. Hyperthermia was applied to
B16F10 cells in one or three courses of 10-min incubation in $42{ }^{\circ} \mathrm{C}, 5 \% \mathrm{CO}_{2}$ atmosphere in the same time schedule as was done during in vivo treatment ( 3 x HT on days 0,4 , and 7). The non-treated cells were kept under the same conditions in $37^{\circ} \mathrm{C}$. Freshly isolated spleen cells of either tumor-bearing or healthy animals were heated for $10 \mathrm{~min}$ at $42^{\circ} \mathrm{C}$ (Fig. 5C, 5D) immediately before the experiment, while non-treated effector cells were kept in $37{ }^{\circ} \mathrm{C}$ (Fig.5A,B) in a roundbottomed 96 well plate. ${ }^{51} \mathrm{Cr}$-labeled B16F10 target cells after HT treatment (none, 1 x HT and 3 x HT as indicated in Fig. 5) were washed and seeded onto splenocytes in E:T ratio 32:1. The cytotoxicity was measured in a standard 4-hour ${ }^{51} \mathrm{Cr}$-release assay.

Heat treatment of effector cells exhibited a strong inhibition of cytotoxicity against untreated B16F10 targets that was more pronounced in healthy animals (down to $26 \%$, Fig. 5A vs. 5C) than in tumorbearing ones (to $41 \%$, Fig. 5B vs. 5D). Further significant suppression was noted in cytotoxic activity of healthy splenocytes, when heat-treated melanoma cells were used as targets (Fig. 5A). No marked difference was seen between the 1 or 3 courses of HT. On the other hand, splenocyte cytotoxicity of tumor-bearing animals responded to $1 \mathrm{x}$ HT $\mathrm{B} 16 \mathrm{~F} 10$ melanoma target cells by significant increase of cytotoxic effector function, not present in $3 \mathrm{x}$ HT (Fig. 5B).

The presented results demonstrate an inhibitory 
influence of HT on effector cells, which is well known in the case of tumoricidal temperature ranges $\left(\mathrm{T} \geq 42{ }^{\circ} \mathrm{C}\right)$. However, the response of effectors to heat-treated melanoma cells evoke an opposite cytotoxicity effect in healthy (remains suppressed - Fig. 5A, 5C) and tumorbearing animals (is stimulated - Fig. 5B, 5D). Moreover, the results in Figures 5B and 5D showed preferable use of one course of hyperthermia.

\section{Discussion}

One of the causes of cancer progression is the failure of tumor cells recognition by the immune system. In this study we revealed an increased count of activated monocytes in B16F10 melanoma microenvironment, which is poorly recognized by the immune system. These monocytes are potent antigen presenting cells (APCs), facilitating more effective identification of tumors by other immunocompetent cells. Here we showed an increase of cytotoxicity against the melanoma cells (Fig. 4), which we also observed in vitro in the case of splenocytes, derived from melanoma-bearing animals (Fig. 5B). The lack of antigen presentation accounts for the decreased cytotoxicity from our in vitro studies, where splenocytes from healthy animals were not primed for the killing of target cells by the shedded antigens (Davies and Lindmo 1990) (Fig. 5A, 5C). The prior contact with melanoma cells and subsequent priming of the immune system seems to be crucial for effector function of cytotoxic cells.

Ex vivo functional assays using B16F10 cell line as target demonstrated an attenuation of cytotoxicity by anesthetics, which returned to the control level after LHT application (Fig. 4A). On the other hand, the natural cytotoxicity against YAC-1 targets was not impaired by the use of anesthetics (Fig. 4B). Assuming that the total cytotoxicity against B16F10 targets involves both the natural and specific components, we have found the specific immunity (CTLs) to be predominant in B16F10 melanoma killing. Thus, the anesthetics affect either the specific immunity itself, or the antigen presentation, which is required for its proper function.

According to the literature, HT-induced changes involve an increase of tumor immunogenicity via induction of hsp70 expression (Clark and Menoret 2001), MHC II- (Michalek et al. 1992) and MHC I-mediated antigen presentation (Ito et al. 2001). Our results showing the tumor infiltrating monocyte activation, increase in CTL, and NK cell numbers in the spleen and stimulation of specific and natural cytotoxic activity under local hyperthermia are a contribution to the data on the involved cell subpopulations.

In conclusion, our study demonstrates significant changes in the distribution, phenotype, activation, and effector function of immune cell subpopulations in tumors and spleens of experimental animals after LHT. We suggest that the hyperthermia enhances tumor cell antigenicity, thus leading to improved recognition of these cells by the infiltrating monocytes. Activated monocytes then presumably present antigens to further cell subpopulations (Th, CTL), priming them for the effector function, as reflected in the increased counts of NK cells and CTLs in the spleen and their cytotoxic activity. As presented in the in vitro studies, the prior contact with tumor cells seems to be crucial for mounting this response. There are probably several pathways involved in the immunostimulatory effects of hyperthermia. The exact mechanisms and involved subpopulations require further investigation.

\section{Conflict of Interest}

There is no conflict of interest.

\section{Acknowledgements}

The study was supported by GAUK 92/2004/C, and GAAVCR-5020403, 500200620, and Institutional Research Concept AV0Z50200510.

\section{References}

ATANACKOVIC D, NIERHAUS A, NEUMEIER M, HOSSFELD DK, HEGEWISCH-BECKER S: $41.8{ }^{\circ} \mathrm{C}$ whole body hyperthermia as an adjunct to chemotherapy induces prolonged $\mathrm{T}$ cell activation in patients with various malignant diseases. Cancer Immunol Immunother 51: 603-613, 2002.

BARONZIO G, GRAMAGLIA A, FIORENTINI G: Hyperthermia and immunity. A brief overview. In Vivo 20: 689$695,2006$.

BASU S, SRIVASTAVA PK: Fever-like temperature induces maturation of dendritic cells through induction of hsp90. Int Immunol 15: 1053-1061, 2003. 
CLARK PR, MENORET A: The inducible Hsp70 as a marker of tumor immunogenicity. Cell Stress Chaperones 2: 121-125, 2001.

DAVIES CD, LINDMO T: Hyperthermia-induced shedding and masking of melanoma-associated antigen. Int $J$ Hyperthermia 6: 1053-1064, 1990.

EMAMI B, NUSSBAUM GH, TENHAKEN RK, HUGHES WL: Physiological effects of hyperthermia: response of capillary blood flow and structure to local tumor heating. Radiology 137: 805-809, 1980.

FIŠEROVÁ A, KOVÁŘŮ H, HAJDUOVÁ Z, MAREŠ V, STAREC M, KŘEN V, FLIEGER M, POSPÍŠIL M: Neuroimmunomodulation of natural killer (NK) cells by ergot alkaloid derivatives. Physiol Res 46: 119-125, 1997.

HILDEBRANDT B, WUST P, AHLERS O, DIEING A, SREENIVASA G, KERNER T, FELIX R, RIESS H: The cellular and molecular basis of hyperthermia. Crit Rev Oncol Hematol 43: 33-56, 2002.

HUANG YH, HAEGERSTRAND A, FROSTEGARD J: Effects of in vitro hyperthermia on proliferative responses and lymphocyte activity. Clin Exp Immunol 103: 61-66, 1996.

ITO A, SHINKAI M, HONDA H, WAKABAYASHI T, YOSHIDA J, KOBAYASHI T: Augmentation of MHC class I antigen presentation via heat shock protein expression by hyperthermia. Cancer Immunol Immunother 50: 515$522,2001$.

KAMPINGA HH, DYNLACHT JR, DIKOMEY E: Mechanism of radiosensitization by hyperthermia $\left(\geq 43{ }^{\circ} \mathrm{C}\right)$ as derived from studies with DNA repair defective mutant cell lines. Int J Hyperthermia 20: 131-139, 2004.

MICHALEK MT, BENACERRAF B, ROCK KL: The class II MHC-restricted presentation of endogenously synthesized ovalbumin displays clonal variation, requires endosomal/lysosomal processing and is up-regulated by heat shock. J. Immunol 148: 1016-1024, 1992.

MILANI V, NOESSNER E: Effects of thermal stress on tumor antigenicity and recognition by immune effector cells. Cancer Immunol Immunother 55: 312-319, 2006.

OSTAPENKO VV, TANAKA H, MIYANO M, NISHIDE T, UEDA H, NISHIDE I, TANAKA Y, MUNE M, YUKAWA S: Immune-related effects of local hyperthermia in patients with primary liver cancer. Hepatogastroenterology 52: 1502-1506, 2005.

SHEN R-N, LU L, YOUNG P, SHIDNIA H, HORNBACK NB, BROXMEYER HE: Influence of elevated temperature on natural killer cell activity, lypmhocyte-activated killer cell activity and lectin dependent cytotoxicity of human umbilical cord blood and adult blood cells. Int J Radiation Oncol Biol Phys 29: 821-826, 1994.

STAWARZ B, ZIELINSKI H, SZMIGIELSKI S, RAPPAPORT E, DEBICKI P, PETROVICH Z: Transrectal hyperthermia as palliative treatment for advanced adenocarcinoma of prostate and studies of cell-mediated immunity. Urology 41: 548-553, 1993.

SZMIGIELSKI S, SOBCZYNSKI J, SOKOLSKA G, STAWARZ B, ZIELINSKI H, PETROVICH Z: Effects of local prostatic hyperthermia on human NK and T cell function. Int J Hyperthermia 7: 869-880, 1991.

VAN DER ZEE J: Heating the patient: a promising approach? Ann Oncol 8: 1173-1184, 2002.

VARTAK S, GEORGE KC, SINGH BB: Antitumor effect of pre-transplantation local hyperthermia and augmentation by dietary unsaturated fat. Indian J Exp Biol 34: 825-832, 1996. 